\title{
Ecos da violência na literatura brasileira contemporânea
}

\author{
Rondinele Aparecido Ribeiro ${ }^{1}$ \\ http://lattes.cnpq.br/2700622346619882 \\ https://orcid.org/0000-0002-6966-2614
}

Enviado em: 06/09/2019

Aceito em: 07/11/2019

RESUMO: A literatura contemporânea é marcada por diversas possibilidades de escrita, sobressaindo, portanto, uma multiplicidade de formas, que não necessariamente precisam se sobrepor uma a outra, mas sim conviverem de maneira harmônica. Como uma das possibilidades expressivas desse mosaico artístico, destaca-se a violência, vertente relevante na configuração do cenário literário nacional devido sua imanência à constituição do país. Dessa forma, intentamos com este artigo, analisar como se configura essa temática em alguns textos da literatura mais recente.

Palavras-chave: Literatura Contemporânea. Violência. Multiplicidade.

Abstract: Contemporary literature is marked by several possibilities of writing, thus highlighting a multiplicity of forms, which do not necessarily need to overlap each other, but coexist harmoniously. As one of the expressive possibilities of this artistic mosaic, violence stands out, a relevant aspect in the configuration of the national literary scenario due to its immanence to the country's constitution. Thus, we intend with this article to analyze how this theme is configured in some texts of the most recent literature.

Keywords: Contemporary Literature. Violence. Multiplicity.

\section{Introdução}

O crítico Antonio Candido (1987), ao se referir ao cenário contemporâneo, assinala o traço de desumanização decorrente da amplificação em múltiplos fluxos nos quais os sujeitos se inserem na contemporaneidade. Esses aspectos, para o autor, intensificaram-se nesse contexto de deslocamentos e guardam relações inerentes com o acentuado processo de exclusão típico de países periféricos. O ponto de vista do crítico reverbera as consequências do cenário desencadeado pela globalização, tais como o inchaço populacional das metrópoles, o capitalismo brutal provocado pela intensificação do processo de industrialização, responsável por motivar “[...] a transformação das populações rurais em massas miseráveis e marginalizadas" (CANDIDO, 1987, p. 203).

Como manifestação discursiva complexa capaz de edificar e humanizar o homem, a literatura torna-se um agente cultural fértil em provocar o sujeito em sua vivência por possibilitar a experimentação de uma realidade, muitas vezes, alheia às experiências cotidianas. Mesmo que num período atravessado por inúmeras dificuldades, desafios e percalços responsáveis por ameaçar a existência humana, a literatura mantém-se fértil, sobretudo, pela

\footnotetext{
${ }^{1}$ Mestrando em Letras pela UNESP-ASSIS (linha Literatura e Estudos Culturais). Membro do GP Cultura Popular e Tradição Oral: Vertentes. Contato: rondinele-ribeiro@bol.com.br
} 
particularidade de contar com traços múltiplos de tendências, de suportes, de escritores e de leitores. Essa manifestação conta, ainda, com um espaço institucionalizado para contribuir, de maneira expressiva, com a transformação da sociedade devido sua potencialidade legitimada pela crítica para se efetivar em um universo discursivo tomando como plano de fundo o cotidiano vivido transformado num discurso capaz de promover, mais que identificação e embate, uma ampliação dos horizontes de expectativas do leitor.

Enquanto produção discursiva engajada, a literatura não se desvincula do processo histórico no qual está inserida. Dessa particularidade, emerge uma vasta produção capaz de manter um diálogo fecundo com o cenário atual. Pode-se dizer, então, que uma possibilidade de análise da ficção contemporânea é analisá-la, sob o rótulo de um discurso engajado. Conforme salienta Maria Zilda Cury (2007), a literatura brasileira apresenta-se com raízes fincadas no solo urbano, mostrando obras em que a substituição do cenário rural pela vida agitada e violenta das grandes cidades é recorrente. Nas palavras da autora: "O espaço da cidade assume feição performática, exibido em cenas rápidas, sketches que rompem com formas enunciativas consagradas, deslocando técnicas de gêneros narrativos, sob o olhar de narradores também eles condenados ao seu movimento vertiginoso" (CURY, 2007, p. 09).

A autora explica, ainda, que há uma forte imposição de um desafio para a crítica literária a partir da problematização institucionalizada em tentar definir a gênese dessa vertente, agrupando e avaliando o conjunto de obras publicadas na contemporaneidade. "Tais textos formam verdadeiros mapas literários, que intercambiam suas fronteiras, partilhando caracterizações e desenhando novas geografias da nossa literatura” (CURY, 2007, p. 08). Também sobressai nas considerações da estudiosa a concepção de que, na ficção contemporânea, quando se trata do espaço rural, há o enfoque a partir do personagem morador da metrópole, revelando a condição de uma ficção, que capta os inúmeros fluxos e deslocamentos sofridos pelos sujeitos contemporâneos.

Ao se referir ao estágio da produção literária atual, Schøllhammer (2009), aponta uma heterogeidade de temas e de formas capazes de viverem de forma harmoniosa:

a ficção brasileira contemporânea não pode ser entendida de modo satisfatório na clave da volta ao engajamento realista com os problemas sociais, nem na clave do retorno da intimidade do autobiográfico, pois, nos melhores casos, os dois caminhos convivem e se entrelaçam de modo paradoxal é fértil (SCHØLLHAMMER, 2009, p. 16).

Sobressai no ponto de vista do crítico a concepção de que a literatura contemporânea é marcada por diversas possibilidades de escrita, destacando-se uma multiplicidade de expressões, que não precisam se sobrepor, mas sim conviverem de maneira harmoniosa. Ao trazer à tona essa impossibilidade de autoafirmação de uma tendência, o autor se aproxima das definições propostas por Beatriz Resende (2008) de que prevalece no cenário atual uma verdadeira multiplicidade de formas reveladas “[...] na urgência da presentificação e [na] dominância do trágico, em angústia recorrente, com a inserção do autor contemporâneo na grande cidade, na metrópole imersa numa realidade temporal de trocas tão globais quanto barbaramente desiguais" (RESENDE, 2008, p. 33).

Nesse inventário marcado pela diversidade e pela multiplicidade, Resende (2008) destaca três aspectos regulares: a presentificação consistente na inquietação de se tratar dos aspectos do cotidiano, facilmente percebidos pela sua apresentação estética, posto que se notabiliza em textos miniaturizados e nos temas bastante atuais; a forte presença do trágico,

https://periodicos.unifap.br/index.php/letras

Macapá, v. 9, n. 1, $1^{0}$ sem., 2019 
que prevalece na vida e no destino dos personagens; e o da violência, que se demonstra como uma manifestação estética que opera um descentramento, trazendo para o centro da discussão as minorias e as massas excluídas.

Regina Dalcastagnè e Laeticia Jensen Eble (2017), ao tratarem acerca do processo de exclusão na sociedade brasileira, salientam que essa mazela social não se constitui apenas como um processo econômico, mas se estende a inúmeros aspectos cotidianos do brasileiro, perpassando o social, o político, cultural e afetivo dos indivíduos excluídos dos espaços institucionalizados de poder e dos espaços onde se efetivam a cidadania. Assim, para as autoras, ao representar situações calcadas nessa vertente, a literatura:

Com isso, não poderia deixar de refletir, e mesmo se posicionar, sobre as profundas desigualdades sociais que marcam esse país e que se traduzem em violências de todo o tipo, da exclusão física à humilhação diária de integrantes de grupos marginalizados, passando ainda pelo não reconhecimento da força e da beleza de suas manifestações artísticas (DALCASTAGNÈ; EBLE, 2017, p. 11).

Como marca estilística, a narrativa contemporânea manifesta-se sob os tons do esfacelamento, da fragmentação, da compressão de culturas, da velocidade e, ainda, da intensidade. Vale dizer que a representação da vertente expressiva ligada à violência e à exclusão não se dá somente pelo conteúdo, mas pela forma, pela linguagem chocante, ágil, veloz, intensa e direta. Assim, do ponto de vista estilístico, pode-se atribuir ao conjunto ficcional recente o rótulo de narrativa marcada pela brevidade, pela concisão, por recursos que dão voz e vez para as personagens subalternas marcadas pela dubiedade e por todas as incertezas dos sujeitos em crise. "São textos que chegam, muitas vezes, a constituir um gênero literário novo, modulado numa narrativa formalmente marcada pela concisão e rapidez, como registros ininterruptos de realidades em movimento célere e que não têm repouso" (CURY, 2007, p. 11).

Nesse contexto, a representação do cenário urbano e dos seus desdobramentos é tratada de modo mais performático, uma vez que passou a se constituir num espaço problemático devido ao cenário da globalização, responsável por acentuar ainda mais as exclusões, o que representa o surgimento de novas configurações identitárias e novos problemas para serem representados. $\mathrm{Na}$ verdade, esse espaço é configurado a partir de movimentos com grande celeridade, contando com cenas também muito rápidas. Outro aspecto a ser observado liga-se aos narradores, que atuam sob uma submissão célere de suas representações, configurando amplamente o processo de representação e significação do urbano numa narrativa breve, que desafia os limites do gênero a que pertence.

Ampliando esse quadro acerca das características estilísticas da literatura contemporânea, convém destacar, ainda o ponto de vista de Ana Paula Franco Nóbile Brandileone e Vanderleia Oliveira (2013). As autoras, recorrendo às ponderações de Schøllhammer (2009), apresentam algumas características da nova narrativa manifestada por formas breves e pela linguagem fragmentada absorvida pelas mídias:

manifesta na linguagem narrativa pelos vazios na página escrita, por cortes abruptos no tempo e espaço diegéticos, manifesta na linguagem narrativa pelos vazios na página escrita, por cortes abruptos no tempo e espaço diegéticos, bem como por múltiplos planos temporais e espaciais que se interpenetram, comprometendo a coerência e contribuindo para a instauração do caos que, não raro, se associa às personagens, cada vez mais problemáticas; anti-heróis em permanente dissonância com o mundo (BRANDILEONE; OLIVEIRA, 2014, p. 25- 26).

O ponto de vista das autoras é assertivo, principalmente, quando se constata que as 
principais marcas empregadas para tecer a escrita da contemporaneidade residem na preferência pelo emprego da temática da violência, manifestada em narrativas fragmentadas, que revelam o descentramento do sujeito ao mesmo tempo em que esses textos trazem à tona as possibilidades de discussão acerca da exclusão e da marginalização das massas e amplificam o debate por revigorarem a escrita literária recorrendo a uma escrita breve, que reflete a urgência da presentificação e da intensidade no cenário marcado pela fluidez facilmente observada nas narrativas pela incorporação constante da existência de um narrador de grau zero, que se omite comportando tal qual uma câmera ligada à particularidade do mostrar com intensidade e velocidade. Por esse motivo, observam-se relações ainda mais profícuas entre o cinema e a expressão literária.

\section{A representação da violência em algumas obras da ficção recente}

Como reflexo da linha expressiva ligada à representação da violência, insere-se a produção literária de Luiz Vilela, marcada pela adoção de um estilo que prima pela incorporação de diálogos breves travados entre personagens. Para Brandileone (2013), essa particularidade revela-se como mais uma caractesística absorvida da cultura de mídia. Assim, esse narrador em grau zero marca uma nova forma de escrita em que a estética do impacto se mostra como um filão a ser explorado. Essa característica pode ser facilmente percebida no conto Catástrofe em que o leitor, de forma abrupta, é introduzido ao conflito travado pelas personagens personagens de modo direto por meio da supressão da voz típica do narrador:

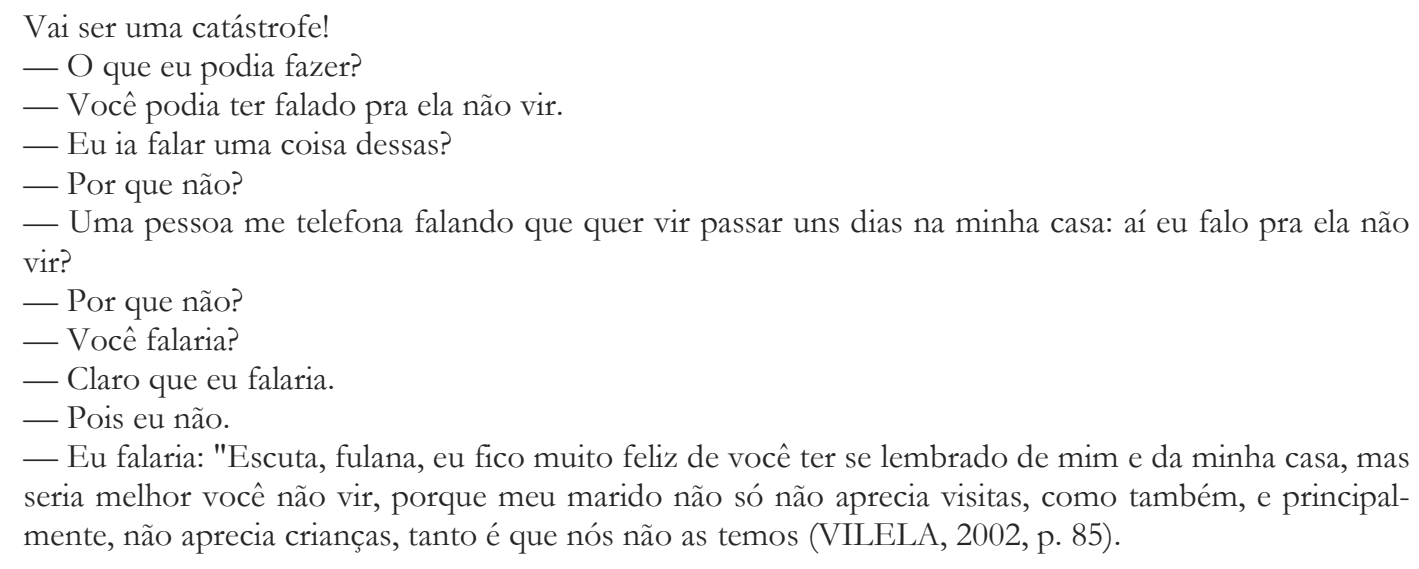

Esses diálogos revelam a presença desse narrador em grau zero para se apresentar uma verdadeira estética do impacto responsável por tencionar a ação e instaurar um conflito conjugal entre Arthur e sua esposa apresentado pela possibilidade de chegada de uma família da cidade de São Paulo, que vem passar o feriado prolongado com o casal. O trecho inicial do conto comprova uma das marcas estilísticas inerentes à produção literária recente caracterizada pela dispensa da voz responsável por intermediar o discurso narrativo. Dessa forma, para se ter a apresentação imediata da ação e do impacto ganha contornos expressivos. Pode-se assinalar que esse narrador apresenta uma proximidade com a câmera do texto audiovisual. Nessa perspectiva, para Brandileone (2013), a literatura deixa de ser mediação e passa a ser ser imediação por desejar apresentar ao leitor de forma direta "como reprodução imediata do real" (BRANDILEONE, 2013, p. 24).

Outra particularidade observada na produção contemporânea brasileira, que emerge como uma linha de força, liga-se à fluidez do tempo e do espaço associada à violência e à 
exclusão, haja vista a literatura converter-se num espaço de apresentação e problematização das consequências da globalização, em sua essência, assinalada por espaços excludentes e marginalizados. Em suma, o conjunto de narrativas ligada a essa vertente revela um rol de textos atravessadas pela ausência de uma ordem linear temporal bem como pela inexistência de um espaço definido devido à fluidez das personagens no espaço em que habitam.

Avançando nas especificidades da cena literária nacional, Cury (2007), ao tratar acerca da reconfiguração do espaço na literatura brasileira contemporânea, ressalta que a representação do espaço urbano nas narrativas contemporâneas é feita de maneira desgastada. A lógica que opera em tais narrativas é a substituição do espaço rural pela organização violenta e agitada das metrópoles. Para a autora, tal representação figurativiza a impossibilidade de se reconstituir uma identidade positiva do país, ganhando uma feição performática, sobretudo, pelo emprego de cenas rápidas, que rompem com as formas enunciativas canonizadas.

Como exemplo dessa característica, situamos o romance As Fantasias Eletivas, do escritor catarinense Carlos Henrique Schroeder. Lançado em 2014, o romance narra a trajetória de duas personagens excluídas: Renê, um recepcionista de hotel e Copi, uma travesti argentina, que se prostitui para sobreviver. Além da trajetória de exclusão, filão ao qual a literatura também capta em sua integridade, as duas personagens têm em comum a trajetória de deslocamento e de fragmentação peculiares ao sujeito contemporâneo. O romancista, ao empregar uma linguagem ágil, praticamente, elimina a presença mediadora do narrador.

Nas primeiras linhas do romance, o leitor é apresentado ao protagonista Renê:

\begin{abstract}
Chegou rubro ao banheiro, lavou o rosto, olhou-se no espelho. Precisava se controlar, não podia colocar tudo a perder de novo, ela não merecia. Mas era como uma chave de fenda, que ia ao fundo, dilarecando o peito. E chorou mais uma vez, por ser fraco, por não controlar esse monstro, por não estar curado. Seria esta a palavra correta, curado? Como se cura algo que é de sua natureza? Como se separam óleo e água depois de misturados? Estragara sua vida de tal maneira havia alguns anos que, quando se entregou para o mar, nem as ondas o quiseram, e uma onda furiosa o devolveu para a areia. Cuspido pelo mar e pela morte, lhe restava levantar e caminhar. Será que ela estaria lá ainda? [...] (SCHROEDER, 2014, p. 13).
\end{abstract}

Percebe-se, a partir do trecho transcrito, a marca estilística do autor em recorrer ao um estilo intenso e veloz para apresentar o protagonista ao leitor. Ainda que não ocorra a preponderância do "narrador em grau zero", por meio da representação das ações iniciais de Renê, percebe-se sua fragmentação, visto que o ciúme doentio com que ele se relaciona com as pessoas é uma problemática, que o acompanha desde criança como se pode perceber no trecho transcrito: "lembrou de sua mãe e da primeira vez que sentiu ciúmes, quando seu irmão mais velho ganhou o melhor presente do pai, o maior carinho da mãe. Tudo isso foi há muito tempo, num Natal qualquer” (SCHROEDER, 2014, p. 14).

Divorciado, o protagonista quase matou o filho e a ex-esposa, além de ter tentado o suicídio e não ter conseguido. Por esse motivo, a personagem é obrigada a viver isolada da família, mudando-se para Santa Catarina na cidade de Balneário Camboriú a fim de reconstruir sua vida. Nessa cidade turística, Renê torna-se recepcionista de um hotel e passa boa parte do tempo limpando o tampo de granito da mesa da recepção com álcool, motivo pelo qual acaba recebendo o apelido de Mister Álcool.

Ainda que a tentativa de rotular a expressão literária empregando um critério temporal possa resultar insuficiente devido às peculiaridades existentes sobretudo no que se refere à multiplicidade de autores, gêneros e formas, de acordo com Schøllhammer (2009, p.17), “ a questão de época e de geração insiste e produz ainda leituras sugestivas para entender a 
ficção produzida num determinado momento”. Assim, o autor explica que uma das soluções mais recorrentes é eleger uma década e buscar nela características que sejam capazes de englobar sua produção literária. Ao seguir esse critério, o autor rotula a década de 1970 como a década dos contistas urbanos; a década de 1980 é concebida como a década da literatura "pós-moderna" devido a multiplicação de nomes e de modalidades literárias; por fim, a década de 1990, conforme o crítico, pode ser vista como geração transgressora "num tempo determinado pela escrita de computador e pela temporalidade imediata da internet".

Ganha destaque como força expressiva dessa última década o rol daqueles que cultivam uma escrita de caráter naturalista capaz de desafiar os limites entre a representação do real e do ficcional. Como representantes desse grupo, podem ser inclusos Paulo Lins e Férrez. O primeiro escreveu o romance Cidade de Deus; o segundo, escreveu a obra Capão Pecado. Ambos os romances têm em comum o fato de representarem o espaço periférico e a marginalização do sujeito, acentuando para uma força expressiva da literatura contemporânea, que se volta para a representação de segmentos excluídos da sociedade sob a ótica de sujeitos pertencentes a esses espaços revelados no texto por uma linguagem predominantemente constitutiva por traços da oralidade típicos das margens, como salienta Paulo Roberto Tonani do Patrocínio (2016).

Para o autor, a literatura surgida a partir dos anos 2000 tem inspiração comunitária e aciona estratégias oriundas em movimentos sociocomunitários. Nas palavras do estudioso: a Literatura Marginal - termo genérico autoproclamado para designar os muitos autores periféricos - pode ser lida como uma forma de engajamento literário realizada por agentes envolvidos na construção de novos lugares de enunciação" (PATROCÍNIO, 2016, p. 29).

O ponto de vista do crítico pode ser explicado, quando se analisa que os sujeitos dos discursos nessa linha de expressão mais recente são constituídos por vozes legitimadas para tecerem suas denúncias contra um sistema opressor e excludente. Vista sob essa perspectiva, a atuação de Paulo Lins e Ferrez no cenário literário brasileiro revela uma situação em que a representação das mazelas é feita sob um olhar de "dentro do periférico" e não mais apenas por vozes instituídas por escritores e intelectuais, que ficcionalizavam essa realidade excludente sem dela pertencerem.

Voltando às obras constitutivas dessa linha denominada de marginal, Cidade de Deus tem como intuito retratar as transformações ocorridas pelo conjunto habitacional de mesmo título da obra, enfocando a pequena criminalidade vivenciada nos anos 60 até a situação caótica vivenciada nos dos anos 90 sob o dominío da acentuada violência e do expressivo tráfico de drogas. Por sua vez, Capão Pecado, focaliza o drama experimentado por Rael, jovem sonhador da periferia, que nutre o desejo de se tornar escritor. De forma paralela a esse sonho, a narrativa é construída sob os designíos de um cotidiano coletivo marcado pela marginalização do ser humano em um espaço de exclusão social onde se acentuam a violência em suas mais variadas expressões perpassadas pelo domínio do trágico como atesta Resende (2008).

Como exemplo fértil dessa vertente trágica da qual Resende (2008) trata, destaca-se a obra Calibre 22, do escritor Rubem Fonseca. Os contos reunidos no livro são permeados pela fragmentação e pela atmosfera trágica. As narrativas da obra de Fonseca estão inseridas na ficcionalização da realidade evidenciando que a realidade é um forte componente para inspirar a matéria literária. Sobressai, dessa forma, no conjunto de textos, a temática cotidiana tratada com uma linguagem intensa e veloz que o ficcionalista domina perfeitamente.

Como exemplo do trágico e da violência, analisaremos dois contos do livro: Colégio e 
Homem não pode bater em mulher. Ambos, além de serem narrados em $1^{\mathrm{a}}$ pessoa, o que não elimina a intensidade e velocidade com que os fatos são apresentados para o leitor, são regidos pela atmosfera trágica criada a partir da focalização dos narradores sujeitos das ações.

Em Colégio, um estudante da periferia apresenta seu cotidiano. A temática da violência é narrada sob a ótica de um aluno morador da periferia, que desnuda, por meio de uma linguagem intensa e veloz, como se operam as relações acentuadas pela exclusão e pela violência nos corredores escolares da periferia onde a dominação do espaço impõe-se pela ordem, subjugando o mais fraco. O narrador é um dos dominados nessa relação:

\begin{abstract}
No meu colégio tem três garotos que andam sempre juntos, a Gangue dos Tiradentes. Dizem: "nós somos a Gangue dos Tiradentes, porque quando brigamos arrancamos os dentes do cara que está brigando com a gente". Os três são muito fortes, quer dizer, um deles é muito gordo, mas um gordo muito gordo é tão perigoso quanto um magro parrudo. Eu evito passar perto deles. Quando isso acontece, eles me empurram e dizem "sai da frente, magrelinho de merda, quer levar porrada?". Eu me afasto o mais rápido possível. Sou mesmo magrelinho, mas não sou de merda, tenho vontade de dizer. Sou mesmo magrelinho, mas não tenho coragem (FONSECA, 2017, p. 38).
\end{abstract}

Na sequência, o narrador conta sobre a relação de amizade mantida com Ivo, um garoto homossexual, vítima de agressões no banheiro:

Eu estava conversando com o Ivo quando apareceu no banheiro a Gangue dos Tiradentes.

"Olha quem está aqui”, disse o Gordo, agarrando o Ivo pelo pescoço.

Os outros dois, os Parrudos, tiraram a calça do Ivo e começaram a enfiar os dedos no cu dele.

"Você gosta de levar pica, não gosta", disse um dos Parrudos enfiando dois dedos no cu do Ivo.

Ivo chorava. Eu sai de mansinho. Não tive coragem nem de ir falar com seu Libório, da portaria (FONSECA, 2017, p. 38).

Destaca-se no trecho o emprego da linguagem carregada e intensa para apresentar para o leitor as ações perpassadas pelo domínio da violência no ambiente escolar. A partir do ocorrido, o protagonista sente-se covarde, mas planeja uma vingaça. Pega a navalha utilizada pelo pai para fazer barba e a leva para a escola.

No outro dia, no banheiro, o grupo, ao aparecer para tentar agredi-lo, sofre um ferimento: "Eu tirei a navalha do bolso e dei um leve corte na bochecha do Gordo. Ele recuou, assustado. Os dois Parrudos também recuaram” (FONSECA, 2017, p. 39).

Rubem Fonseca integra o grupo de escritores que recorrem ao emprego do "brutalismo feroz". Essa característica, é importante acrescentar, diferencia-se da técnica de outros escritores que normalmente recorrem ao narrador em $3^{a}$ pessoa. Nesse sentido, vale a intepretação da obra fonsequiana empreendida pela crítica Vera Lúcia Follain de Figueiredo (2003), que vê na escrita de Fonseca não apenas um simples registro de casos policiais perpassados por cenas violentas ou ainda um mero mosaico de crimes disformes apresentados ao leitor de modo aleatório.

Prosseguindo no domínio do trágico, no conto Homem não Pode Bater em Mulher, a temática recai na violência doméstica. Narrado em primeira pessoa, o protagonista apresenta-se como um excluído do mercado de trabalho por ter sido obrigado a se aposentar por invalidez devido um atropelamento:

Eu trabalho desde os quatorze anos. Quer dizer, trabalhava, me aposentei por invalidez quando tinha cinquenta. Eu trabalhava como arquivista, não sei por que gostava de ficar guardando pastas naqueles arquivos de metal. Eu não queria me aposentar, mas fui obrigado. Tudo porque sempre fui muito 
distraído. Andava nas ruas, não via nada do que estava acontecendo, não via pessoas, nem bichos, nem prédios, nem vitrines, nem carros. Resumindo, essa maneira distraída de não ver as coisas em torno de mim acabou de uma maneira desagradável. Fui atropelado por um carro ao atravessar uma rua e, no pronto-socorro, cortaram a minha perna (FONSECA, 2017, p. 41).

A partir do ocorrido, o narrador passa a encarar a vida de modo mais atencioso.

$\mathrm{Na}$ sequência, apresenta o casal de velhinhos surdos e o casal formado por um homem de olhinhos e uma mulher de olhos pequenos. A vizinha vivia com manchas pelo corpo. O protagonista perguntou ao marido qual a causa das manchas no corpo da vizinha e acabou sendo agredido com um soco.

A partir dessa agressão sofrida, a personagem compra um revólver e planeja assassinar o vizinho agressor:

Então acendi a luz, olhei a minha caderneta do banco para ver quanto dinheiro eu tinha guardado. Dava para ver o que eu queria. Procurei o Antônio Pinóquio, Pinóquio não era o nome deke, era um apelido, porque o nariz dele era comprido e pontudo, mas ele não se incomodava de ser chamado de Antônio Pinóquio. Eu conhecia porque trabalhamos juntos na mesma repartição, eu como arquivista e ele, como ... já esqueci. Enfim, o Antonio Pinóquio tinha o que eu precisava e disse, como você sempre foi meu cupincha, vou te cobrar uma pechincha. Coloquei a coisa dentro de uma saca que o Antonio Pinóquio me deu e voltei para o meu prédio (FONSECA, 2017, p. 44).

Após narrar suas intenções em assassinar o vizinho, a personagem focaliza as ações do crime em si apresentadas de forma natural e sem provocar ressentimentos no sujeito: "Foi fácil dar um tiro naquela cabeça grande. Ele caiu duro no chão do corredor. Fui para o meu apartamento. Tirei a perna e deitei feliz" (FONSECA, 2017, p. 44). Com efeito, o discurso da personagem revela traços de uma experiência urbana embrutecedora, que encontra eco na temática da violência, reveladora das consequências de acentuado processo de metropolização desordenado típico de países periféricos em que pessoas de diversas classes sociais transitam num espaço opressor. Assim, a literatura, enquanto sistema de representação, encarna a reprodução complexa dessa experiência crescente no país nos mais diversos espaços ( interior, campo, sertão ou cidade) por meio da escrita artística.

\section{Considerações Finais}

A relação entre literatura e violência pode ser destacada sob o rótulo da imanência. Presença recorrente no país, estende-se do período colonial à contemporaneidade, época marcada pela acentuação do processo de modernização, que culminou no crescimento dos grandes centros urbanos. Essa excrecência se apresenta de forma visível no cotidiano do país, constituindo-se como uma vertente expressiva da ficção, que encontrou na literatura um forte componente para se converter num fator de representação, dadas as especificidades do meio em dialogar com a realidade.

Marcada por diversas possibilidades de escrita, à literatura nacional recente pode ser atribuída a peculiaridade de se notabilizar por uma multiplicidade de temas e de formas, as quais não necessariamente precisam se sobrepor uma a outra, mas sim conviverem de maneira harmônica como muito bem enfatizam Resende (2008) e Schøllhammer (2009). A partir dessa constatação, salientamos que, enquanto manifestação artística, a literatura apropria-se da realidade vivida para problematizá-la. Assim, ao incorporar a violência como uma vertente expressiva, ela reafirma sua vocação em se constituir como um espaço institucionalizado para representar os dilemas da sociedade na qual se insere. 
No que tange à violência, é importante acrescentar ainda que a representação dessa temática preferencialmente encontra terreno fértil no espaço urbano, comprovando a tese proposta por Cury (2007). Para a crítica literária, a ficção nacional recente apresenta-se vinculada ao solo urbano devido as particularidades de uma nação que experimenta um movimento alinhado à globalização perpassado pela vida

agitada e violenta que domina as metrópoles. Dessa forma, a literatura, ao referenciar aspectos perversos da modernização acentuados pela temática da exclusão social, reafirma sua vocação de se vincular a uma instância consagrada no plano discursivo para discutir temáticas ligadas à problematização do sujeito.

\section{Referências}

BRANDILEONE, Ana Paula Franco Nobile; OLIVEIRA, Vanderléia da Silva. A narrativa brasileira no século XXI: Ferréz e a escrita do testemunho, Navegações, Porto Alegre, v. 7, n. 1, p. 23-30, jan.-jun. 2014.

BRANDILEONE, Ana Paula Franco Nobile; PATROCÍNIO, Paulo Roberto Tonani do. Os ricos também morrem, de Ferréz: Por uma dicção Lírico-prosaica do universo periférico. In: OLIVEIRA, Vanderléia da Silva; VALENTE, Thiago Alves. Desafios contemporâneos: novas leituras. Campinas, SP: Pontes Editores, 2018.

BRANDILEONE, Ana Paula Nobile. Literatura brasileira contemporânea: caminhos diversos. In: BRANDILEONE, Ana Paula Nobile; OLIVEIRA, Vanderléia da Silva (Org.). Desafios contemporâneos: a escrita do agora. São Paulo: Annablume, 2013. p. 17-33. CANDIDO, Antonio. A educação pela noite \& outros ensaios. São Paulo: Ática, 1987. CANDIDO, Antonio. Vários escritos. $3^{a}$ ed. São Paulo: Duas cidades, 2003.

CURY, Maria Zilda Ferreira. Novas geografias narrativas. Revista Letras de hoje, Porto Alegre: EDIPUCRS, v. 42, n. 4, p. 7-17, 2007.

DALCASTGNÈ, Regina; EBLE, Laeticia Jensen. Apresentação. In: DALCASTGNÈ, Regina; EBLE, Laeticia Jensen. (orgs.). Literatura e Exclusão. Porto Alegre, Rio Grande do Sul: Editora Zouk. 2017. p. 11- 14.

FIGUEIREDO, Vera Lúcia Follain de. Os crimes do texto: Rubem Fonseca e a ficção contemporânea. Belo Horizonte: UFMG, 2003.

FONSECA, Rubem. Calibre 22. 2. Ed. Rio de Janeiro: Nova Fronteira, 2017.

PATROCÍNIO, Paulo. Cidade de lobos: a representação de territórios marginais na obra de Rubens Figueiredo. Belo Horizonte: Editora UFMG, 2016.

RESENDE, Beatriz. A Literatura Brasileira num mundo de fluxos. Revista Terceira Margem. Rio de Janeiro, Número 23, p. 103-112.

RESENDE, Beatriz. Contemporâneos: expressões da literatura brasileira no século XXI. Rio de Janeiro: Casa da palavra/Biblioteca Nacional, 2008.

SCHØLLHAMMER, Karl Erik. Ficção brasileira contemporânea. Rio de Janeiro: Civilização Brasileira, 2009.

SCHROEDER, Carlos Henrique. As Fantasias Eletivas. Rio de Janeiro: Record, 2014. VILELA, Luiz. Catástrofe. In: A cabeça. Cosac \& Naify: São Paulo, 2002. 